\title{
Using Phenomenological Methodology with Thematic Analysis to Examine and Reflect on Commonalities of Instructors' Experiences in MOOCs
}

\author{
Chi-Cheng Chang ${ }^{1, *}$ and Yao-Hua Wang ${ }^{2}$
}

1 Department of Technology Application and Human Resource Development, National Taiwan Normal University, Taipei 106, Taiwan

2 Information Technology Center, National Taiwan Normal University, Taipei 106, Taiwan; wang@ntnu.edu.tw

* Correspondence: samchang@ntnu.edu.tw

Citation: Chang, C.-C.; Wang, Y.-H. Using Phenomenological Methodology with Thematic Analysis to Examine and Reflect on Commonalities of Instructors' Experiences in MOOCs. Educ. Sci. 2021, 11, 203. https:// doi.org/10.3390/educsci11050203

Academic Editor: João Piedade

Received: 7 February 2021

Accepted: 15 April 2021

Published: 26 April 2021

Publisher's Note: MDPI stays neutral with regard to jurisdictional claims in published maps and institutional affiliations.

Copyright: (c) 2021 by the authors. Licensee MDPI, Basel, Switzerland. This article is an open access article distributed under the terms and conditions of the Creative Commons Attribution (CC BY) license (https:// creativecommons.org/licenses/by/ $4.0 /)$.

\begin{abstract}
Instructors' experiences in MOOCs assist their curriculum development and teaching skills as well as professional growth, which is seldom explored. The study examined and reflected on the commonalities of instructors' experiences in Massive Open Online Courses (MOOC) based on phenomenological methodology with thematic analysis. By summarizing the commonalities in phenomenology from the implicit experiences of the instructors who were interviewed, commonalities of MOOC instructors' experiences were found to be the following: (1) affinity-knowing how to provide MOOC material that is approachable; (2) ability to tell a story-knowing how to write and direct a video that contains a story or scenarios for classes as innovative teaching; (3) macro attitude-broadening a learner's horizon is more important than lecturing on knowledge; (4) altruism - concerning the welfare of students rather than personal fame and fortune; and (5) learning by doing - having a passion for innovative teaching and bravely implementing it. Finally, several suggestions and inspirations were given based upon the reflections on the commonalities of MOOC instructors' experiences.
\end{abstract}

Keywords: instructor experience; experiential commonality; MOOC; phenomenology

\section{Introduction}

Massive Open Online Courses (MOOC), as an educational revolution, come as a great change to traditional higher education [1]. MOOCs are platforms of knowledge diffusion in the new era and immediately become a focal point [2]. The best qualities of MOOCs are that they are free, open, and flexible. MOOCs provide an instructional environment that is learner-centered, cooperative, open, and innovative [3]. Moreover, MOOCs provide autonomous learning, diverse learning content, and convenient interaction. MOOCs allow students to have their own learning plans by providing a new instructional environment with a large number of students. Additionally, they give teachers a chance to experience a new instructional mode. Therefore, the aim of the development of MOOCs is not only to establish a platform that makes learning easier, but also to develop a flexible learning and teaching environment (Mackness, 2013) [4].

MOOCs have been a matter of debate and research since they appeared, with Downes and Siemens pioneering version in 2018 [5]. Previous studies mainly adopted quantitative methods and focused on learners, followed by design-, context-, impact-, and instructorfocused studies [6,7]. Experience is the best teacher [8], therefore, instructor experiences on curriculum development and teaching in MOOCs are the best teachers for MOOCs instructors. Instructor experiences may include challenges [9], roles in MOOCs [10], the changes of roles [11], and so forth. The adoption of qualitative methods that explore lived experiences within MOOCs are not a novelty, with previous studies covering students' discourses, as well as teachers' and designers' opinions. However, the number of articles 
dealing with a rigorous phenomenological approach applied to instructors is less frequent, while the general accounts on user-experiences are numerous in the literature $[12,13]$. According to the study of Raffaghelli, Cucchiara, and Persico [14], the phenomenology was excluded in the most commonly adopted methods in academic research on MOOCs during the period between January 2008 and May 2014. Therefore, phenomenology was adopted in the study for describing MOOC instructors' experiences and examining the experiential commonalities through the researcher's reflections on the instructors' experiences.

\section{Theoretical Basis}

\subsection{Dewey's Theory of Experience}

Experience is what is happening to humans all the time and, therefore, always consists of actual life experiences of individuals. Experience reveals the following concepts: experience manifests itself in and has passions; experience integrates over space and time; experience is a moving force; and experience is transformation [15]. Dewey's theory of experience argued that experience arises from the interaction of two principles, continuity and interaction [16]. Continuity refers to the concept that all experiences are carried forward and influence future experiences (p. 35). Interaction occurs between an individual, objects, and other people (p. 42). For instance, teaching experience on a course will depend on how the teacher teaches the course, as well the teacher's past teaching experience of similar courses and students.

Dewey's theory of experience initially emphasized student learning experience. However, it can be extended to teachers' teaching experience. The value of teachers' teaching experience can be examined via the effect that experience has on the teachers' present, their future, and the extent to which the teachers can make a contribution to students, schools, and society. Teachers can provide valuable experiences only because they have gone through and been exposed to similar experiences. Additionally, it is only through various significant experiences that they become experienced as teachers [15] (p. 18). Educators should regard teaching and learning as a continuous process of reconstructing experiences.

\subsection{Instructor Challenges in MOOCs}

Although there were many students registering for courses, the low completion and retention rates were a serious problem [17]. Regarding completion rate or incentives for degrees, MOOCs were not as effective as traditional schools [18]. The current MOOCs are facing serious issues regarding quality [19], sustainability, awarding of credit, and low completion rates [12]. Most people enjoyed cost-free means, provided by MOOCs, meaning they could participate in lifelong learning more conveniently. In addition, MOOCs facilitate innovative developments for instructions and establish global learning communities; however, some people believe that MOOCs cannot be a substitute for face-to-face communication and, owing to their loose features, cannot be seen as higher education. They consider MOOCs to be a trend that will soon disappear [20].

According to Lin and Cantoni [21], some instructors' motivations to teach MOOCs were because of their universities' interests in MOOCs and pressures from their executives. They were invited by their universities, who intended to enter the MOOC market, or by MOOC platforms offering MOOCs on specific subjects. However, some of them were happy to take the challenge of trying new technologies and tools. Some instructors were to teach using MOOCs voluntarily because of their subject matter expertise and shared passions.

Cohen and Holstein found that, from student perceptions, instructors were a leading factor that contributed to the success of MOOCs [22]. However, MOOC instructors face four challenges, including: (a) a lack of students' reactions; (b) a lack of instant feedback, such as expressions; (c) a large amount of time and money, especially since more time is spent on the development of teaching materials and course progressions than in traditional classroom teaching; and (d) online assessments for large numbers of students [9]. Buhl, Andreasen, and Pushpanadham [23] claimed that teachers were once the key person responsible for development, implementation, and evaluation of conventional courses, but those tasks, in 
MOOCs, might now be performed by a collaborative team or some persons with various responsibilities. Gil-Jaurena and Domínguez asserted that a big challenge was the creation of collaborative teams which supported the teachers' designs and plans for implementation of MOOCs [10]. Therefore, instructors chose to avoid the risk of implementation of MOOCs and stayed away from innovative teaching activities [21].

In sum, the challenges faced by MOOC instructors are related to teaching practices. What instructors experienced was called experiential knowledge, which is helpful for instructors to practice their teaching skills and enhance their professional abilities.

\subsection{Instructor Roles in MOOCs}

Online instructors, who are intellectuals, are required to reflect on and challenge their own professional and authoritative roles and positions. Since learner autonomy is promoted and knowledge selection is diverse, the role of online instructors altered significantly $[10,23]$. The role of instructors has been changed from being an expert in a particular field to a learning facilitator, meaning that the relationship between instructors and students develops as one of learning partners [11]. The role of teachers using MOOCs is to stimulate and facilitate student motivation and achievement [24].

Buhl et al. [23] stated that a key change on the role of MOOCs' instructors in term of students' learning processes in the MOOCs was spread across different persons with various tasks, such as a presenter in videos, a digital content writer, a multimedia instructional designer, and so forth. Gil-Jaurena and Domínguez [10] explored the evolution of instructors' roles in MOOCs by surveying their experiences of MOOCs in terms of their current tasks and the main changes compared to teaching in a more conventional online or e-learning environment. The biggest changes of teaching roles in MOOCs compared to conventional online courses were reduced instructor presence and reduced interaction with learners. The second most common change was that assessment was less demanding in MOOCs and required less involvement from instructors. The third most common change was more involvement in MOOC course design than in implementation [10].

Hew and Cheung [9] investigated the reasons why instructors offered MOOCs in universities. Some instructors were willing to explore teaching using MOOCs because they were curious about the large amount of students who come from diverse backgrounds, therefore, they were willing to take the challenge of this new instruction mode. They believed that teaching experiences were helpful for generating various perspectives $[9,21]$. Another reason that they were willing to teach using MOOCs was the egoistic or selfcentered motivation, as they believed that MOOC platform could attract a large amount of students. In this way, they could establish their prestige and increase the profits from the market $[9,21]$. Many participants believed that instructors could be an important factor for them to choose a course, meaning that they made choices based on instructors rather than schools $[9,22]$. Furthermore, the altruistic motivation was another reason that instructors were willing to teach MOOCs. Education is a business with a conscience, indicating that a mission for instructors is to teach and solve problems, so MOOCs can educate more people and be beneficial to more students [9].

In short, the issues above should be of concern to instructors in universities, because of the changes to traditional courses, instructors, and higher education that MOOCs bring.

\subsection{Importance of Instructor Experiences in MOOCs and Theory of Phenomenology}

In the study, "instructor experiences" refer to instructors' descriptions on their curriculum development and teaching experiences in MOOCs, including courses, instructions, participants, and other relevant people and events. The study focused on the effects of instructors' intentionality on curriculum development and teaching experiences in MOOCs, and how they described their inner thoughts and experiences through the curriculum and teaching. In other words, the emphasis was how the instructors perceived "the way they have done certain things or the way certain things have been given to them in their consciousness." For instructors, lots of students from everywhere, with unfamiliar back- 
grounds, is a great shock and a new challenge [25]. Therefore, instructors' experiences in MOOCs assist the development of their curriculum and teaching skills, as well as professional growth [9]. Moreover, the value of MOOCs lies in certification and confidence in teachers' knowledge achievement [24].

Most research questions about phenomenology are relevant to researchers' personal experiences, and extended by a phenomenon that the researcher is interested in [26]. The phenomenological methodology emphasizes life experiences, which reflects a particular person's experiences toward changes in a certain environment. The exploration of the experiences is beneficial for people to reflect the development of the future life. Although Zhu, Bonk, and Sari [5] explored instructors' experiences in designing MOOCs using a mixed method, including considerations and challenges, their study excluded instructors' other important experiences, such as delivery of, belief in, and passion for MOOC instruction, and so forth. This study examined research paradigms and massive open online courses (MOOC) topics to increase our understanding of the MOOC phenomenon and methodological issues. In addition, the study presented a perspective from the instructors' selected across a time span, using a thick description of the instructors' life experiences going through the several stages of preparing and delivering an MOOC.

\subsection{Research Questions}

Based on the background above, the research questions were as follows: (1) What were instructors' experiences in MOOCs, including teaching challenges and roles in instructional media design, instructional delivery, instructional belief, instructional devotion, and instructional passion, and so forth? (2) What were the experiential commonalities and reflection of instructors in MOOCs from the phenomenological approach? Experiential commonality or commonality of experiences means the common, similar, and associated experiences between different people that can be obtained through the process of comparison, connection, convergence, and refinement on the meaningful lexicons in textual data from their oral descriptions [27].

\section{Method}

\subsection{Participant}

Two popular instructors who taught on a platform of MOOCs-ShareCourse (http: / / www.sharecourse.net; accessed on 26 April 2021) — were selected for exploring their teaching experiences. The platform offers college courses on science, engineering, social science, and so forth. The two instructors are Instructor A, whose course was the most popular on the platform, and Instructor B, whose course was the most popular in the field of computer science. The courses taught by Instructor A and Instructor B were named "Ocean Windows-Oceanographic Museum and Sea World" and "Introduction of Internet of Things", respectively. The two courses have been implemented on the MOOCs platform more than 10 years. Figures 1 and 2 present the screenshots of the two MOOCs.

Case 1-Instructor A, about 60 years old, is a chair professor of marine science with the specialty of museology, marine ecology, and tourism. The courses, which feature live-action video, are about the applications and history of marine technology. Case 2-Instructor $\mathrm{B}$, who is about 40 years old, is a professor of computer science with experience in the industry. Courses mainly introduce the basic concepts and technologies for the 'internet of things'. Course content starts from the development of the Internet and the application of cellphone to the introduction about the advantages of the 'internet of things' on the web. 


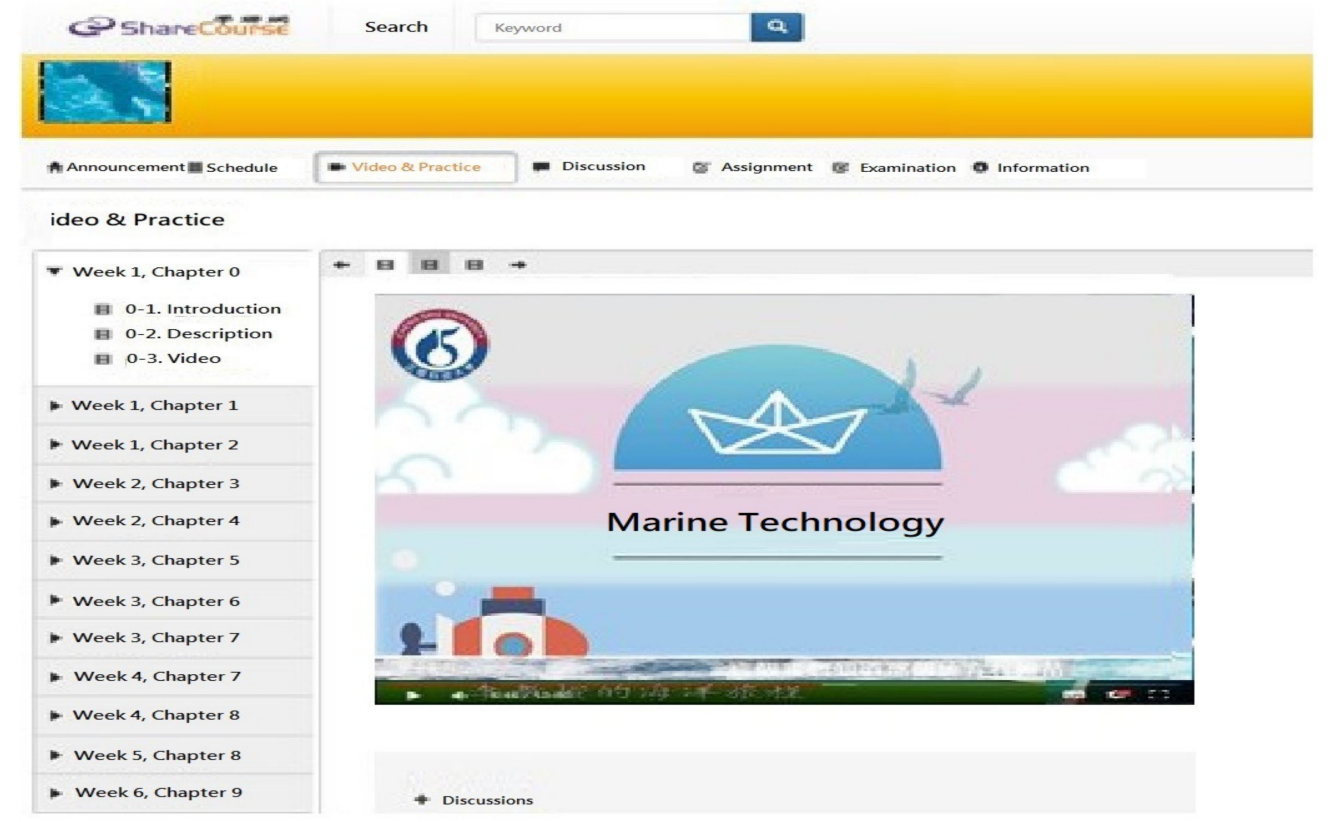

Figure 1. The learning material for week 1 in the course of "Ocean Windows-Oceanographic Museum and Sea World".

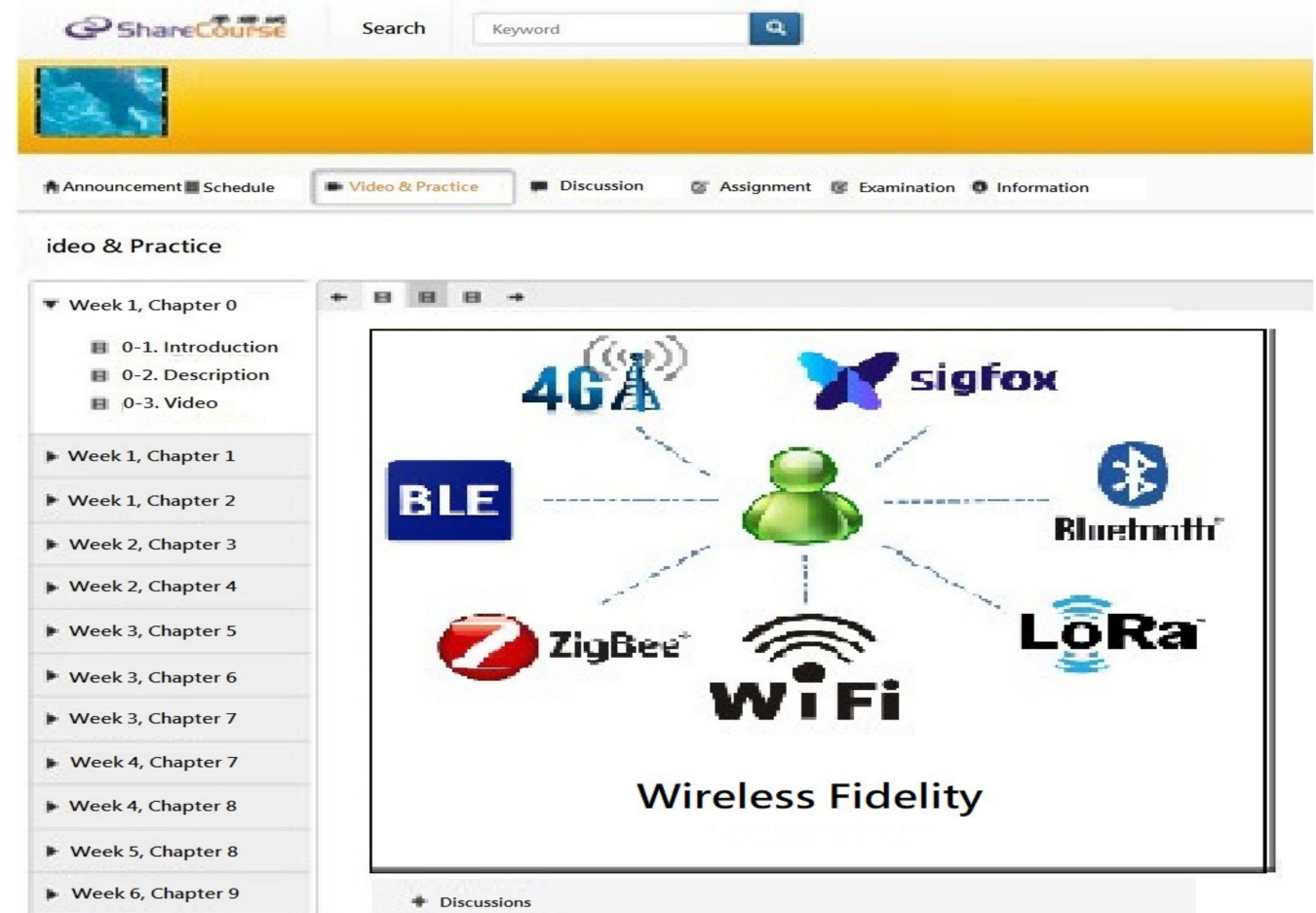

Figure 2. The learning material for week 1 in the course of "Ocean Windows-Oceanographic Museum and Sea World".

\subsection{Data Gathering}

Interview is the most commonly used research method for phenomenological studies [28]. The most effective and direct research method for phenomenology is through interviews, which are a helpful way for understanding schools $[9,22]$. The perspective of phenomenology reflects that the experiences exist in a situational context with ductility. 
In order to understand the commonalities of the experiences, events about the past, the present, and the future, should be expressed orally and in writing.

The interview topics were determined by three stages of the deep interview with phenomenology including: (a) helping interviewees to construct their experiential contexts; (b) assisting interviewees to construct their experiences; and (c) encouraging interviewees to reflect on their experiences (Cerbone, 2014) [29]. Therefore, the key elements for asking questions in the three stages, based on previous literatures, included: (a) their experience contexts about teaching MOOCs with why and how; (b) how they choose and decide their plans and designs toward MOOCs, as well as what they have done differently from the normality about choices, and what innovations they have made in the process of practice; and (c) their reflections on curriculum development and teaching experiences in MOOCs by inquiring of their thoughts toward future plans for MOOCs, which allows interviewees to reflect on what they changed and gained after teaching with MOOCs.

Meaningful lexicons did not exist in the description of the text, but were generated depending on the researcher's ability to construct interviewees' experiences instead [26]. Thus, the researcher did his best to enrich his professional sensitivity, including reading relevant literature, and understanding the status about the promotion of MOOCs in universities. When interviewing, the researcher did his best to listen interviewees to speak out their experiences, not to limit interviewees' talks. The interviewer put away his or her own teaching perspectives toward MOOCs and then listened carefully to interviewees' descriptions. The researcher sometimes provided timely feedback but did not interrupt, which was helpful for interviewees to describe their thoughts. The interviewed voices were recorded in audio tapes and transcribed into textual data by the researcher. Finally, the textual data were sent to the interviewees for correction and revision. According to phenomenologists, the data of the conscious experience are called Capta, which represents what is seen, thought, and felt [30].

\subsection{Data Analysis}

The study followed the steps for the analyses in phenomenology as follows: (1) repeatedly listening to interviewees' descriptions on experiences in order to comprehend them thoroughly; (2) converting experiences into textual data; (3) recognizing the meaningful lexicons in textual data within the study scope, from the perspective of psychology; and (4) reorganizing the meaningful lexicons in textual data and summarizing the description about the commonalities of phenomenon in experiences [27,29]. Following the steps above, two coders jointly induced the thematic codes through repeated discussions. The coders were composed of the interviewer and a professor whose specialty was on MOOCs and phenomenological analysis.

We referred to Guest, MacQueen, and Namey's [31] systematic approaches of applied thematic analysis, including the concepts of explanatory analysis, codebook development, data reduction techniques and cluster analysis. In fact, thematic analysis is relevant to phenomenology since it stresses subjects' perceptions, feelings, and experiences subjectively [31]. The thematic analysis in the study was conducted via the process of coding in the following six phrases: familiarization with data, generating initial codes, searching for themes among codes, reviewing themes, defining and naming themes, and producing the final report [32]. We examined and re-examined the textual data to generate meaning and further refined the themes. The techniques for generating meaning include noting patterns and themes, clustering cases, making contrasts and comparisons, partitioning variables, and subsuming particulars [33].

The coders began thematic analysis by reading the transcripts and writing initial themes (sometimes called pre-set or priori codes) for categories based on the techniques above and the principles of instructional design [34], concepts of e-learning and instructional science [35], and the authors' teaching experiences. They then revised the categories of the initial themes through combining, dividing, or refining actions until primary or main themes (sometimes called emergent codes) describing the instructors' experiences 
emerged. The five themes were finally refined and induced as follows: instructional and media design (IMD), instructional delivery (DEL), instructional belief (BEL), instructional devotion (DEV), and instructional passion (PAS). We examined and re-examined the textual data to generate meaning and further developed the themes. The code for the themes on personal experiences was a set of three English letters and two numbers. The first letter represented Instructors A and B (A, B). The second letter to the forth letter represented the five experience themes. The last two numbers were the codes for sentences' orders in descriptions for themes $(01,02,03, \ldots, 20,21, \ldots)$. The explanation of the code scheme is shown in Table 1. The qualitative analysis software-MAXQDA (Published by the VERBI $\mathrm{GmbH}$, Berlin, Germany), was adopted for word count, word search, taxonomic analysis, constant comparison analysis, and so forth.

Table 1. Code scheme for themes on instructors' MOOC experiences.

\begin{tabular}{ccc}
\hline $\begin{array}{c}\text { First Letter } \\
\text { (Teacher Code) }\end{array}$ & $\begin{array}{c}\text { Second Letter to Forth Letter } \\
\text { (Five Experience Themes) }\end{array}$ & $\begin{array}{c}\text { Last Two Numbers } \\
\text { (Order of Descriptive Sentence in the Theme) }\end{array}$ \\
\hline & $\begin{array}{c}\text { Instructional and media design (IMD) } \\
\text { Instructional delivery (DEL) }\end{array}$ & $01,02,03, \ldots, 09,10,11, \ldots, 20,21, \ldots$ \\
Instructor A & Instructional belief (BEL) \\
Instructor B & Instructional passion (PAS) & \\
& Instructional devotion (DEV). \\
\hline
\end{tabular}

For instance, the code A-IMD-02 represents instructor A's experiences on instructional and media design from the 2 nd sentence of his description; the code B-BEL-21 represents instructor B's experiences on instructional belief from the 21th sentence of his description.

\subsection{Reliability and Validity}

Triangulation [36] was conducted for the data examination and analysis in the study. A total of three people were involved in the triangulation, these included the researcher or corder, the other coder, and the interviewee for each interview. The researcher first transcribed the tape-recorded interviews and analyzed meaningful lexicons of experiences. Afterwards, the other coder reviewed the meaningful lexicons of the experiences in the data and the experiential commonalities. Finally, the researcher discussed with interviewees for re-checking the commonalities of the experiences and revising them. All transcripts were imported into the qualitative analysis software (MAXQDA) by both coders who worked independently on the same transcript.

To increase the validity for descriptions, the researcher's familiarity towards MOOC affairs, and the dialogs with interviewees before interviews, enhanced interviewees' trust in the researcher, and encouraged interviewees to say whatever they wanted. When interviewing, the researcher cooperated closely with interviewees in order to gain enough detail in descriptions of experiences. The researcher was open minded and did not limit the interview content within a subject during the interviews. Moreover, the researcher put his own thoughts aside and listened carefully to interviewees' descriptions. The researcher extensively accepted interviewees' viewpoints and clearly understood interviewees' descriptions of experiences.

Giorgi [27] believed that the meaningful lexicons did not only exist in the description of the text, but also existed in the researcher who was trained professionally. To increase the interpretive validity, the researcher analyzed and explained with his or her professional sensitivity and open mind, which would completely express the commonalities of experiences. Furthermore, the researcher analyzed interviewees' commonalities of experiences based on his or her objective attitude, and carefully established meaningful lexicons of interviewees' experiences. Finally, the researcher discussed with third parties, who participated in MOOC affairs and understood instructors' teaching experiences, in order to obtain feedback for examining study results. 
The percentages or proportions of agreement between the two coders for each thematic category applied to the transcribed text were computed based on the following formulation [37]. In Table 2, the individual percentage of agreement between the two coders for each thematic category are all greater than 0.8 , which reached the sufficient consistencies between both coders in each categorical coding [38,39].

$$
\text { Inter }- \text { coder agreement percent } P=\frac{2 \mathrm{M}}{\mathrm{N}_{1}+\mathrm{N}_{2}}
$$

Table 2. Inter-coder agreement and reliability.

\begin{tabular}{ccc}
\hline Theme & Inter-Coder Agreement & Composite Reliability \\
\hline Instructional and media design (IMD) & 0.93 & 0.964 \\
Instructional delivery (DEL) & 0.92 & 0.958 \\
Instructional belief (BEL) & 0.88 & 0.936 \\
Instructional devotion (DEV) & 0.89 & 0.942 \\
Instructional passion (PAS). & 0.91 & 0.953 \\
\hline
\end{tabular}

Based on Holsti's [40] formula below, the composite reliabilities (CR), the other type of coding reliability, for each thematic category are all greater than 0.8 , indicating a high reliability in the coding work [41].

$$
\text { Composite/compound reliability CR }=\frac{\frac{\mathrm{nP}}{1+[(\mathrm{n}-1) \mathrm{P}]}}{(\mathrm{n}=2 \text { coders in the study })}
$$

M: Both coders' joint agreement amount

$\mathrm{N}_{1}$ : Coder 1's agreement amount

$\mathrm{N}_{2}$ : Coder 2's agreement amount

$n$ : Number of coders

$\mathrm{nP}: \mathrm{n} \times \mathrm{P}$

The study used the inter-coder agreement function in the qualitative analysis software (MAXQDA) to obtain the results of inter-coder agreement and reliability in Table 2. After negotiating the remaining coding discrepancies, the study finally reached almost full agreement between both coders.

\section{Results}

\subsection{Association between Instructor Attribution and Thematic Category}

Table 3 presents a contingency table about the relationship between instructor attribution and thematic category. The numbers in each cell represent the thematic frequencies occurred from instructors' descriptions of experiences. The result of chi-square test $\left(\chi^{2}=219.890, p<0.001\right)$ for instructor attribution and thematic category indicates a significant association between the two variables. The association strength is strong and reaches a significant level (Cramer's V $=0.709$, Contingency Coefficient $=0.708, p<0.001$ ). The results above reveal that there is a significant difference in the distribution of frequency, of the thematic category, between two types of instructor attribution. Given that heterogeneity in the thematic category between different instructors, it made instructors' experiences being presented diversely. The consistency in the frequency of the thematic category between two types of instructor attribution is statistically significant (Kappa $=0.099, p<0.001)$, implying the reliability of the contingency table is satisfied. The results above indicate instructors' experiences are not only diverse but also consistent. It implies that the interview data and coding results are reliable to support the study. 
Table 3. Contingency table and chi-squire test of relationship between instructor attribution and thematic category.

\begin{tabular}{cccc}
\hline Thematic Category & \multicolumn{2}{c}{ Instructor Attribution } & \multirow{2}{*}{ Total } \\
\cline { 2 - 3 } & Science & Engineering & 39 \\
Instructional and media design (IMD) & 21 & 18 & 48 \\
Instructional delivery (DEL) & 23 & 25 & 45 \\
Instructional belief (BEL) & 24 & 15 & 33 \\
Instructional devotion (DEV) & 18 & 16 & 30 \\
Instructional passion (PAS) & 14 & 95 & 219 \\
Total & 100 & 21 & \\
\hline
\end{tabular}

$\chi^{2}=219.890^{* * *}$ Likelihood Ratio $=152.190^{* * *}$ Cramer's V $=0.709^{* * *}$ Contingency Coefficient $=0.708^{* * *}$

Kappa $=0.099 * * *$

$* * * p<0.001$

\subsection{Instructional Media Design-Converting Traditional Lecture Contents to Digital Videos}

In order to meet the instruction style of MOOCs, the contents of lectures should be converted into videos. However, how do the instructors deal with the conversion?

Instructor A had experiences in broadcasting of popular science program, so he knew that a good program must be directed and expressed with different levels, and even makes viewers able to predict the future. As Instructor A said: "I know that a good popular science program must have a scenario and director, including a complete expression method and thoughts with different levels." (A-IMD-01)

As Instructor B said: "Young people should be given new things. The product can be seen from new knowledge. Using this way to edit and direct teaching materials will effectively attract students because it would be like reading science fictions." (B-IMD-01, B-IMD-02)

In sum, both instructors believed that when directing instructional videos, the content of the videos needs to have different levels, and allow students to imagine the future.

As mentioned by Instructor A, "A good instruction with videos that students are willing to watch must have some features. Teaching materials need levels and meanings. After expressing cause and effect, students may have interests." (A-IMD-02, A-IMD-03)

Furthermore, Instructor B said: "I wondered how to make people understand the contents that requires more than 10 minutes in just few minutes. Therefore, I integrated some of my thoughts into slides, and added some animations, which would attract students' attentions." (B-IMD-03, B-IMD-04)

From the descriptions of experiences from both instructors, they did not just videotape the lectures in the traditional classroom directly, but wrote and directed the contents of the teaching materials first. In this way, students would understand the lecture and also be attracted by scenarios. Videos should attract students and let them feel that there are a series of stories, which leads them to imagine the possibilities of the future.

\subsection{Instructional Delivery-Delivering Approachable Instruction and Materials}

Since MOOCs are open, instructors had no idea about students' backgrounds. Therefore, how to demonstrate instructional contents to students who are unable to be seen becomes crucial for instructors. Experiential contexts of commonality can be obtained from two instructors' descriptions about their past experiences.

Instructor A said: "People I interact before are grassroots or from different industries, which shares the same feature as MOOCs (A-DEL-01). We not only teach elites in MOOCs, but also people of all backgrounds. Students' common viewpoints and ideas will be merged." (A-DEL-02)

Instructor B said: "Because the range of internet of things is very broad, teaching robots can also be referred to internet of things. In order to avoid such things, the 
Ministry of Education asks us to visit many schools and give teaching materials to instructors." (B-DEL-01)

In the traditional classroom, besides leadership, being amiable is necessary for pushing massive people forward to engage in certain activities. However, in the online classroom, students are unable to be seen, then how can instructors show their amiable attitudes?

As what Instructor A said, "You must let people to understand what they are. Otherwise, they are meaningless. Therefore, 'Knowing how to deliver messages' will assist students to understand." (A-DEL-03)

The demonstration of MOOC teaching materials does not need a guide because deep principles will not be taught. An instructor should think from students' position rather than deep principles or specialties. As expressed by Instructor A:

"If you bring about students' learning interests at the beginning, they will be willing to listen to the contents." (A-DEL-04)

As Instructor B said: "One should not begin with theories, but begin with applications." (B-DEL-02)

MOOC students only desire to learn what they want to acquire because they do not necessarily learn for certifications. Thus, they are different from the students on campus (Hew \& Cheung, 2014).

Instructor B said: "The course I teach is to introduce products in industries by showing the products to students for realizing conceptions, which is very practical ... Because products represent a process, from the market to technical aspect, package, and cost. And the content will broaden students' horizons ... " (B-DEL-03, B-DEL-04)

As mentioned above, Instructor B thought that, with MOOC, the lectures should contain not only theories, but also practical content. Based on both instructors' descriptions of experiences, the content of MOOCs planned by the instructors were student-centered.

The instruction for MOOCs is different from the instruction for the traditional classroom. As mentioned by Instructor B: "We have done many projects by cooperating with industries, so we have many practical experiences. After we bring back our practical experiences, we think about how to teach students ... " (B-DEL-05, B-DEL-06)

In sum, both instructors would not deliver instruction with theories. Instead, they delivered instruction by engaging with students' relevant life experiences, in order to arouse students' interests, so that students would be willing to listen. Both instructors' descriptions of experiences on the delivery of instructions revealed that the experiential commonalities are to deliver approachable instructional materials.

\subsection{Instructional Belief-Cultivating a Great Horizon Is Important Than Cultivating Little Knowledge}

MOOCs are open and lectures will be spread around the world. Therefore, instructors act more carefully in MOOCs. These phenomena can also be seen in both instructors' descriptions of experiences. As Instructor B mentioned that:

"Because knowledge will be spread in MOOCs, teaching something old will be laughed. Some instructors are unsure whether they teach correctly, so they will not teach the details." (B-BEL-01)

Instructor A thought that there was a change from the traditional classroom to MOOCs: "little knowledge is usually mentioned in class. However, this curriculum is to cultivate a broad horizon, which is a lot more important than knowledge." (A-BEL-01)

MOOCs are able to cultivate students' horizons, which prepares students with the proper tools to stay informed about the current curriculum. Thus, instructors should not only lecture knowledge in detail, but also broaden students' horizon. This idea is mentioned by the two instructors as follows: 
Instructor A said: "I would think about why not let my own stories become audiences' or viewers' own stories? In other words, I will not only lecture on my stuff; instead, I will allow students to develop their own things." (A-BEL-02, A-BEL-03)

Instructor B said: "MOOCs need those people working in the industry to give lectures because their speeches will be useful for students." (B-BEL-02)

Learning through exchanging among individuals or groups is an instructional model that appropriate to MOOCs [42]. How do students learn from diverse resources? Both instructors described their experiences about giving a lecture in an MOOC with diverse resources.

Instructor A said: "Only teaching students what I know would be a waste of this brand new resource. It should be participated by more experts and shared by more students." (A-BEL-04)

Instructor B said: "It is good to find some people working in the industry to film. Not only to talk about theories, but also to lecture practices by people working in the industry. There are products that can be shown for explaining what products that a certain theory has applied." (B-BEL-03, B-BEL-04)

In short, both instructors mentioned that it is important for students to feel that the contents of lectures are useful. A large horizon means a macroscopic content of the instruction that can absorb diverse and practical knowledge. The commonalities of the experiences on MOOCs is "cultivating a great horizon is more important than cultivating little knowledge".

\subsection{Instructional Devotion-Reputation and Benefit Should Be Put Away}

Most instructors felt anxious when agreeing to teach MOOCs [10]. In this situation, the question was asked - what kind of attitude should be held by instructors when accepting to open MOOCs? The following is the instructors' descriptions of their experience.

Instructor B said: "We put the slides on MOOCs for people to see without any charges, and no one will ask you to give a speech or buy your books. Actually, we should not think it in this way." (B-DEV-01)

Instructor A said: "you do not need to care about your gain or loss. All you have to do is your best. When sharing your resources, you will gain more and more chances." (ADEV-01, A-DEV-02)

Both instructors held a viewpoint of not asking for reputation and benefits. What benefits would the instructors get after teaching MOOCs? The following descriptions are both instructors' reflections after teaching an MOOC.

Instructor A said: "When facing those students from different backgrounds, the content that I familiar with is not enough. The questions they asked let me start to think about whether my previous thoughts are wrong." (A-DEV-03)

In short, Instructor A believed that teaching benefits teacher and student alike. He experienced self-growth from this kind of instruction and enriched his teaching experiences.

Instructor B said: "Not only educating others through instructions, my personal industry-university experiences can also be demonstrated, which cannot be copied by others." (B-DEV-02)

These instructors elaborated their instructional knowledge and ability from teaching MOOCs that was similar with the study of Hew and Cheung [9]. Both instructors did not worry about personal gain and loss. The instructors were interviewed experienced MOOC instructions that brought them good trainings and reflections, and even more opportunities.

\subsection{Instructional Passion-Execution of Innovative Instruction}

Both instructors had many experiences of teaching with MOOCs and even possessed thoughts about innovative instructions. 
Instructor A mentioned that when accepting an invitation from a broadcasting station, an innovative way was applied by combining broadcasting and MOOCs and establishing a new instructional platform with an interactive model. Instructor A said:

"If students are still interested in the teaching material after listening, they can have an advanced learning chance, such as interactive function. I expect to adopt innovative ways to attract students to learning online." (A-PAS-01, A-PAS-02)

Instructor B said: "I want to film an ideal lab video with the contents of guidance for students to practice and to conclude in the end. I am also interested in finding new media technologies to simulate the processes of engineering hand-ons and model building." (B-PAS-01, B-PAS-02)

Both instructors expressed the reflections about the experiences on teaching MOOCs, issued challenges to the existing instructional style, and explained their developed innovative instructions. Their extreme passion towards innovative instructions could be strongly felt.

\section{Discussions}

The commonalities of the experiences did not only explore the appearance of the event, but also the thinking process of the person [26]. In other words, regardless of promotions on basic activities or large events, the appearance is to lead people to engage in the activity or event, whereas the depth of the experience is the commonalities of affinity behind the activity or event. In brief, The study found the following commonalities for the instructors' experiences through reflection on the experiences, which were: (1) Affinity-knowing how to provide an approachable teaching material; (2) Ability to tell a story-knowing how to write and direct a video with scenarios for teaching knowledge, which is different from traditional teaching; (3) Macroscopic attitude-cultivating widened horizons is more important than cultivating a narrow set of knowledge; (4) Altruism-personal reputations and benefits should be put away in order to benefit more students since MOOC has already become a new trend; (5) Spirit for learning by doing-being a passionate about innovative instruction methods and trying to execute them. These experiential essences might reflect the instructors' attitude toward implementing MOOCs. Just as Cohen and Holstein [22] stated that the altruistic motivation was one of the reasons that instructors were willing to teach MOOCs. No matter what motivations an instructors in MOOCs possess, he or she need to keep a positive attitude toward implementing MOOCs and hold innovative instruction online to attract students.

According to the commonalities of the experiences above, the interviewees have the following reflections: (1) the Internet has changed people's ways of interactions, so the communication does not have to be face-to-face, and approachable teaching materials on the MOOC platform have shown affinity during instruction; (2) engaging with MOOC instructions can enhance instructors' teaching ability, and, thus, gain more opportunities for the development; (3) in response to MOOC videos, instructors must know how to write and direct teaching materials for attracting students to learn and to enhance learning motivations; (4) instructors should hold a learning attitude for understanding MOOC instructions, and cultivate new teaching disciplines in response to this kind of instructional model; and (5) instructors' responsibilities are to teach students and solve their problems, but the purpose of MOOCs is to cultivate students' ability, so instructors need to activate their instructional methods for broadening students' horizons. As the roles of instructors in MOOCs have changed significantly $[10,23]$, and there are many challenges for implementing MOOCs [10], the instructors need to face the changed roles and challenges raised by positive attitudes and behaviors.

There are three inspirations obtained from the MOOC instructors' commonalities of experiences, including: (1) instructors' knowledge and ability-instructors should know how to demonstrate approachable teaching materials and cultivate professional ability from the practices; (2) instructors' mind-instructors should hold a macroscopic attitude 
and be responsible for teaching and tackling students' problems; and (3) instructors' spiritinstructors should take challenges to give instructions responding to technology. According to deFreitas et al. [17], the quality and interactivity of MOOCs, such as gamified and simulated elements in online material or instruction, could improve the low engagement, as well as the low competition and retention rates. In sum, high quality online material and instruction are critical factors that impact the success of MOOCs.

\section{Conclusions and Suggestions}

Consistent with Dewey's theory of experience, the instructors interacted with their MOOCs teaching experiences, creating continuity from them and deriving their own teaching meanings. MOOC instructors' psychological experiential process can be understood from the commonalities of the experiences. The experiential commonalities base on the context of MOOCs, which belong to philosophical construct. However, not everyone can perceive the experience. Therefore, it is suggested that schools establish trust between instructors and students, which will be helpful for instructors to teach experiential knowledge. Furthermore, supervisors are recommended to hold activities for sharing experiences and to study instructors' core competency, which can be a reference for schools opening MOOCs.

The contributions of the study are that (1) it extends the current understanding of MOOCs by examining and reflecting on the commonalities of instructors' experiences in MOOCs and (2) it adopts phenomenological methodology with thematic analysis that is excluded in previous research on MOOCs. In term of teaching practice, both MOOC instructors' commonalities of experiences can provide MOOC instructors a practical experience for observations. The study results help instructors understand and reflect on the modern emerging instructional style, which inspire instructors and educators to try MOOC instructions, and contribute to the MOOC instructors in course designs and instructional plans. Although the concept framework of the study was based on empirical data, the analysis was descriptive, rather than normative. Instead of solutions or effective instructional skills, the key for the research problems could be the commonalities of instructors' experiences, and provide researchers and instructors a chance to reflect. For the future study, it is suggested to track the instructors' experiences of innovative MOOC instructions, such as experiences of broadening applications or transferring practical courses to MOOCs.

The nature of phenomenology is such that it rejects the concept of objective research and presumes that human behavior should be interpreted subjectively [30]. Given the way the results of the study have been derived from the two interviews, these are their direct descriptions about what happened in their MOOCs experiences. Even though the two MOOCs were popular among students, the results of the study are not necessarily common to other MOOCs, and that is the limitation of the study.

Author Contributions: Conceptualization, C.-C.C.; methodology, C.-C.C.; software, Y.-H.W.; validation, C.-C.C. and Y.-H.W.; formal analysis, Y.-H.W.; investigation, Y.-H.W.; resources, C.-C.C. and Y.-H.W.; data curation, Y.-H.W.; writing-original draft preparation, C.-C.C. and Y.-H.W.; writingreview and editing, C.-C.C.; visualization, Y.-H.W.; supervision, C.-C.C.; project administration, C.-C.C. All authors have read and agreed to the published version of the manuscript.

Funding: This research received no external funding.

Institutional Review Board Statement: Not applicable.

Informed Consent Statement: Not applicable.

Data Availability Statement: Not applicable.

Conflicts of Interest: The authors declare no conflict of interest. 


\section{References}

1. Veletsianos, G.; Shepherdson, P. A systematic analysis and synthesis of the empirical MOOC literature published in $2013-2015$. Int. Rev. Res. Open Distrib. Learn. 2016, 17, 198-221. Available online: http://www.irrodl.org/index.php/irrodl/article/view/24 48/3655. (accessed on 26 April 2021).

2. Bayeck, R.Y.; Hristova, A.; Jablokow, K.W.; Bonafini, F. Exploring the relevance of single-gender group formation: What we learn from a massive open online course (MOOC). Br. J. Educ. Technol. 2018, 49, 88-100. [CrossRef]

3. Kovanović, V.; Joksimović, S.; Poquet, O.; Hennisb, T.; Čukićc, T.; de Vriesb, P.; Hatalae, M.; Siemens, G.; Gašević, D. Exploring communities of inquiry in Massive Open Online Courses. Comput. Educ. 2018, 119, 44-58. [CrossRef]

4. Mackness, J.; Waite, M.; Roberts, G.; Lovegrove, E. Learning in a small, task-oriented, connectivist MOOC: Pedagogical issues and implications for higher education. Int. Rev. Res. Open Distrib. Learn. 2013, 14, 140-159. [CrossRef]

5. Zhu, M.; Bonk, C.J.; Sari, A. Instructor experiences designing MOOCs in higher education: Pedagogical, resource, and logistical considerations and challenges. Online Learn. 2018, 22, 203-241. [CrossRef]

6. Zhu, M.; Sari, A.; Bonk, C.J. A systematic review of MOOC research methods and topics: Comparing 2014-2016 and 2016-2017. In Proceedings of the Conference of EdMedia + Innovate Learning 2018, Amsterdam, The Netherlands, 25-26 June 2018.

7. Zhu, M.; Sari, A.; Lee, M.M. A systematic review of research methods and topics of the empirical MOOC literature (2014-2016). Internet High. Educ. 2018, 37, 31-39. [CrossRef]

8. Goodlad, J.I. A Place Called School; McGraw-Hill: New York, NY, USA, 1984.

9. Hew, K.F.; Cheung, W.S. Students' and instructors' use of massive open online courses (MOOCs): Motivations and challenges. Educ. Res. Rev. 2014, 12, 45-58. [CrossRef]

10. Gil-Jaurena, I.; Domínguez, D. Teachers' roles in light of massive open online courses (MOOCs): Evolution and challenges in higher distance education. Int. Rev. Educ. 2018, 64, 197-219. [CrossRef]

11. McDonald, J.; Reushle, S. Charting the role of the online teacher in higher education: Winds of change. In Proceedings of the 19th Annual Conference of the Australasian Society for Computers in Learning in Tertiary Education, Auckland, New Zealand, 8-11 December 2002.

12. Jona, K.; Naidu, S. MOOCs: Emerging research. Distance Educ. 2014, 35, 141-144. [CrossRef]

13. Liyanagunawardena, T.R.; Adams, A.A.; Williams, S.A. MOOCs: A systematic study of the published literature 2008-2012. Int. Rev. Res. Open Distrib. Learn. 2013, 14, 202-227. [CrossRef]

14. Raffaghelli, J.E.; Cucchiara, S.; Persico, D. Methodological approaches in MOOC research: Retracing the myth of Proteus. Br. J. Educ. Technol. 2015, 46, 488-509. [CrossRef]

15. Roth, W.-M.; Jornet, A. Towards a theory of experience. Sci. Educ. 2014, 98, 106-126. [CrossRef]

16. Dewey, J. Experience and Education; Collier-MacMillan Canada Ltd.: Toronto, ON, Canada, 1938.

17. De Freitas, S.I.; Morgan, J.; Gibson, D. Will MOOCs transform learning and teaching in higher education? Engagement and course retention in online learning provision. Br. J. Educ. Technol. 2015, 46, 455-471. [CrossRef]

18. Daniel, J. Making sense of MOOCs: Musings in a maze of myth, paradox and possibility. J. Interact. Media Educ. 2012, 1-20. Available online: http://www-jime.open.ac.uk/jime/article/view/2012-18. (accessed on 26 April 2021). [CrossRef]

19. Gordon, D.G.; Wiltrout, M.E. A framework for applying the learning sciences to MOOC Design. Front. Educ. 2021, 5, 500481. [CrossRef]

20. Breslow, L.; Pritchard, D.E.; DeBoer, J.; Stump, G.S.; Ho, A.D.; Seaton, D.T. Studying learning in the worldwide classroom research into edX's first MOOC. Res. Pract. Assess. 2013, 8, 13-25.

21. Lin, J.; Cantoni, L. Decision, implementation, and confirmation: Experiences of instructors behind tourism and hospitality MOOCs. Int. Rev. Res. Open Distance Learn. 2018, 19, 1-293. [CrossRef]

22. Cohen, A.; Holstein, S. Analysing successful massive open online courses using the community of inquiry model as perceived by students. J. Comput. Assist. Learn. 2018, 34, 544-556. [CrossRef]

23. Buhl, M.; Andreasen, L.B.; Pushpanadham, K. Upscaling the number of learners. fragmenting the role of teachers: How do massive open online courses (MOOCs) form new conditions for learning design? Int. Rev. Educ. 2018, 64, 179-195. [CrossRef]

24. Berestova, A.; Kondratenko, L.; Lobuteva, L.; Lobuteva, A.; Berechikidze, I. MOOC as an enabler for achieving professional competence: Problem-solving aspect. Int. J. Emerg. Technol. Learn. 2021, 16, 1-16. [CrossRef]

25. Roth, M.S. My modern experience teaching a MOOC. Chron. High. Educ. 2013, 59, 18-21.

26. Van Manen, M. Phenomenology of Practice: Meaning-Giving Methods in Phenomenological Research and Writing; Left Coast Press: Walnut, CA, USA, 2014.

27. Giorgi, A. Sketch of a psychological phenomenological method. In Phenomenology and Psychological Research; Giorgi, A., Ed.; Duquesne University Press: Pittsburgh, PA, USA, 1985; pp. 8-22.

28. Kvale, S. The qualitative research interview: A phenomenological and a hermeneutical mode of understanding. J. Phenomenol. Psychol. 1983, 14, 171-196. [CrossRef]

29. Cerbone, D.R. Understanding Phenomenology, 1st ed.; Routledge: New York, NY, USA, 2006.

30. Beverly, B. Capta: The Data of Conscious Experience. Available online: https://www.informationweek.com/big-data/big-dataanalytics/capta-the-data-of-conscious-experience/a/d-id/282625 (accessed on 2 May 2019).

31. Guest, G.; MacQueen, K.M.; Namey, E.E. Applied Thematic Analysis; SAGE Publications: Thousand Oaks, CA, USA, 2012.

32. Braun, V.; Clarje, V. Successful Qualitative Research: A Practical Guide for Beginners; SAGE Publications: London, UK, 2013. 
33. Miles, M.B.; Huberman, A.M.; Saldana, J. Qualitative Data Analysis: A Method Sourcebook, 3rd ed.; Sage Publications: Thousand Oaks, CA, USA, 2014.

34. Gagné, R.; Briggs, L.; Wager, W. Principals of Instructional Design, 4th ed.; Harcourt Brace College Publishers: Forth Worth, TX, USA, 1992.

35. Clark, R.C.; Mayer, R.E. E-Learning and the Science of Instruction: Proven Guidelines for Consumers and Designs of Multimedia Learning, 4th ed.; John Wiley \& Sons: Hoboken, NJ, USA, 2016.

36. Denzin, N.K.; Lincoln, Y.S. Introduction: Entering the field of qualitative research. In Handbook of Qualitative Research; Denzin, N.K., Lincoln, Y.S., Eds.; SAGE Publications: Thousand Oaks, CA, USA, 1994; pp. 1-17.

37. Corbin, J.; Strauss, A. Basics of Qualitative Research: Techniques and Procedures for Developing Grounded Theory, 4th ed.; SAGE Publications: Thousand Oaks, CA, USA, 2015.

38. Lombard, M.; Snyder-Duch, J.; Bracken, C.C. Content analysis in mass communication: Assessment and reporting of intercoder reliability. Hum. Commun. Res. 2002, 28, 587-604. [CrossRef]

39. Tinsley, H.E.A.; Weiss, D.J. Interrater reliability and agreement. In Handbook of Applied Multivariate Statistics and Mathematical Modeling; Tinsley, H.E.A., Brown, S.D., Eds.; Academic Press: San Diego, CA, USA, 2000; pp. 95-124.

40. Holsti, O.R. Content Analysis for the Social Science and Humanities; Addison-Wesley: Reading, MA, USA, 1969.

41. Neuendorf, K.A. The Content Analysis Guidebook; SAGE Publications: Thousand Oaks, CA, USA, 2000.

42. Conole, G. MOOCs as disruptive technologies: Strategies for enhancing the learner experience and quality of MOOCs. J. Distance Educ. 2013, 39, 1-17. [CrossRef] 